\title{
PENGARUH SALEP EKSTRAK ETANOL DAUN SIRIH (Piper betle) TERHADAP PENYEMBUHAN LUKA IRIS PADA TIKUS PUTIH JANTAN (Rattus norvegicus)
}

\author{
Muhammad Zuhdan Fannani ${ }^{1}$, Taufiq Nugroho ${ }^{2 *}$ \\ ${ }^{1}$ Mahasiswa Pendidikan Dokter Fakultas Kedokteran Universitas Islam Indonesia \\ ${ }^{2}$ Departemen Ilmu Bedah Fakultas Kedokteran Universitas Islam Indonesia
}

\begin{abstract}
ABSTRAK
Latar Belakang

Tanaman obat yang banyak digunakan oleh masyarakat untuk mengobati luka adalah daun sirih (Piper betle). Daun sirih juga banyak dimanfaatkan untuk mengobati sariawan.

\section{Tujuan}

Penelitian ini bertujuan untuk menguji pengaruh salep ekstrak etanol daun sirih terhadap penyembuhan luka iris pada tikus putih jantan (Rattus norvegicus).

\section{Metode}

Penelitian ini menggunakan rancang penelitian eksperimental. Subjek penelitian dikelompokkan secara acak menjadi 3 kelompok. Masing-masing kelompok terdiri dari 10 ekor tikus, kemudian dilukai sepanjang $2 \mathrm{~cm}$ kedalaman $0,5 \mathrm{~cm}$ dan diberi perlakuan yang berbeda. Kelompok I merupakan kelompok perlakuan dengan pemberian salep ekstrak etanol daun sirih. Kelompok II merupakan kontrol positif dengan pemberian povidon iodine $10 \%$, dan kelompok III adalah kontrol negatif dengan pemberian vaselin album. Panjang luka masing-masing kelompok diukur dan diamati setiap hari hingga hari ke-14, kemudian data yang didapatkan dianalisis menggunakan Oneway Anova.
\end{abstract}

\section{Hasil}

Lama penyembuhan luka iris kelompok uji dengan salep ekstrak etanol daun sirih, kelompok uji dengan povidon iodin dan kelompok uji dengan vaselin album berturut turut adalah $10,8 \pm 0,422 ; 11,9 \pm 0,316 ; 13,8 \pm 0,422(p=0,000)$.

\section{Kesimpulan}

Penelitian pada tikus putih jantan (Rattus norvegicus) menunjukkan bahwa salep ekstrak etanol daun sirih mampu mempercepat proses penyembuhan luka. Salep daun sirih dapat dimanfaatkan dan menjadi alternatif terapi baru untuk penyambuhan luka.

Kata Kunci : Salep daun sirih (Piper betle), Penyembuhan luka iris. 


\section{ABSTRACT}

\section{Background}

One of the medicinal plants used to treat wounds is betel leaf. Betel leaf (Piper betle) is also used by Indonesian since the first medication to treat ulcers. However, there is currently no scientific evidence of the effects of betel leaf to accelerate incision wound healing in experimental animals or in humans.

\section{Objective}

The study aims to assess the ethanol extract of Piper betle leaf ointment on the healing of incised wounds in the rats

\section{Methods}

This type of study was purely experimental design. Research subjects were randomly divided into three groups and each group consisted of 10 rats. The incision wound were made 2-cm long and $0.5-\mathrm{cm}$ deep and were given different treatments. Group I was treated with the ointment of betel leaf extract. Group II was a positive control by administering povidone-iodine $10 \%$, and group III was a negative control with the provision of Vaseline-album. The length of incision wound in each group were measured and observed every day until the $14^{\text {th }}$ day, then the data obtained were analyzed using Oneway Anova.

\section{Results}

Wound healing at the ethanol extract of betel leaf group, the povidone-iodine group and the vaseline-album groupwere $10,8 \pm 0,422 ; 11,9 \pm 0,316 ; 13,8 \pm 0,422$, respectively $(p=0,000)$.

\section{Conclusion}

This study showed that the ointment of betel leaf had the shortest healing times. Later, Ointment betel leaf can be utilized and become a new therapeutic alternative for wound healing.

Keywords : Piper betle leaf ointment, incision wound

\section{PENDAHULUAN}

Obat herbal telah diterima secara luas di hampir seluruh negara di dunia. WHO menyatakan bahwa negara-negara di Afrika, Asia, dan Amerika Latin menggunakan obat herbal sebagai pelengkap pengobatan primer yang mereka terima. ${ }^{1}$ Bangsa Indonesia telah lama mengenal dan menggunakan tanaman berkhasiat obat sebagai salah satu upaya dalam menanggulangi masalah kesehatan. ${ }^{2}$ Persentase penduduk Indonesia yang menggunakan obat tradisional dalam pengobatan sendiri terus meningkat selama kurun waktu tujuh tahun (20002006) dari $15,2 \%$ menjadi $38,30 \%{ }^{3}$ Pengobatan tradisional adalah pengobatan dan/atau perawatan dengan cara, obat, dan pengobatnya yang mengacu kepada pengalaman, keterampilan turun temurun, pendidikan/pelatihan, dan diterapkan 
sesuai dengan norma yang berlaku dalam masyarakat. ${ }^{4}$

Indonesia merupakan salah satu negara yang memiliki tingkat kecelakaan lalu lintas yang cukup tinggi. Data dari Kepolisian Republik Indonesia tahun 2009 menyebutkan, sepanjang tahun tersebut terjadi setidaknya 57.726 kasus kecelakaan di jalan raya dan dari data statistik menunjukkan sebanyak 36,5\% mengalami luka ringan. ${ }^{5}$ Pengobatan menggunakan bahan kimia efektif mematikan mikroba, tetapi dapat menimbulkan iritasi, resistensi dan infeksi yang harus diobati dengan obat yang lebih paten, dan harganya semakin mahal, sehingga masyarakat beralih kembali ke obat-obatan traditional yang lebih murah. ${ }^{6}$

Tanaman obat yang banyak digunakan masyarakat untuk mengobati luka adalah daun sirih (Piper betle). Daun sirih sudah dimanfaatkan oleh masyarakat Indonesia sejak dulu untuk mengobati sariawan. ${ }^{7,8,9}$ Daun sirih digunakan dalam pengobatan tradisional sebagai obat kumur, penyegar mulut, pengobatan luka, anti bakteri, anti jamur, antioksidan, dan mengurangi pembentukan plak gigi. ${ }^{10-13}$ Uji klinis salep Piper betle mempercepat perbaikan lesi kulit pada ringworm hingga 26\%. Piper betle gel juga dapat menghambat pertumbuhan dermatofita dan pertumbuhan Candida. ${ }^{6,14}$ Penelitian ini bertujuan mengetahui efek salep ekstrak etanol daun sirih (Piper betle) terhadap percepatan penyembuhan luka iris pada hewan percobaan tikus putih jantan (Rattus norvegicus).

\section{METODE PENELITIAN}

\section{Subjek Penelitian}

Hewan uji yang digunakan adalah tikus putih jantan (Rattus norvegicus) yang diperoleh dari laboratorium terpadu Universitas Islam Indonesia. Jumlah hewan uji yang digunakan berjumlah 30 ekor, dengan berat badan sekitar 150-200 gram dan umur 2-3 bulan dengan masingmasing kelompok berjumlah 10 tikus.

\section{Pembuatan Ekstrak}

Pembuatan ekstrak etanol daun sirih dilakukan di Laboratorium Farmakognosi-Fitokimia $\quad$ Fakultas Matematika dan Ilmu Pengetahuan Alam (FMIPA) Jurusan Farmasi Universitas Islam Indonesia Yogyakarta. Satu kilogram daun sirih dicuci terlebih dahulu, dipotong kecil, kemudian dikeringkan dalam lemari pengering pada suhu $38^{\circ} \mathrm{C}$ selama 5 hari. Daun yang sudah kering diblender hingga menjadi serbuk. Dilanjutkan dengan seratus gram serbuk 
dimaserasi dengan etanol $70 \%$ selama 3 tikus dilukai sepanjang $2 \mathrm{~cm}$ dan hari. Larutan yang terbentuk disaring kedalaman $0,5 \mathrm{~cm}$. Luka dibersihkan untuk mendapatkan ekstrak yang larut dengan air mengalir dan diberi perlakuan dalam etanol, kemudian dievaporasi sesuai kelompok masing-masing. Setiap dengan evaporator pada suhu $50^{\circ} \mathrm{C}$ hingga hari dilakukan pengamatan untuk melihat menjadi pasta. Salep daun sirih dibuat tertutupnya luka tersebut oleh kulit baru. dengan cara sebanyak 10 gram ekstrak Tidak dilakukan penutupan luka atau etanol daun sirih dicampur dengan strapping karena dikhawatirkan akan vaseline album sebanyak 90 gram mengganggu proses penyembuhan luka sehingga mendapatkan konsentrasi ekstrak pada proses penggantian plester saat $10 \%$.

\section{Pengelompokan Hewan Uji}

Tikus putih jantan (Rattus norvegicus) sebanyak 30 ekor dibagi menjadi 3 kelompok secara acak masingmasing kelompok berjumlah 10 ekor tikus. Kelompok I diberi $0,5 \mathrm{mg}$ salep daun sirih 10\%. Kelompok II (kontrol positif) diberi 0,5 povidon iodine $10 \%$. Kelompok III (kontrol negative) diberi vaselin album.

\section{Perlukaan pada Hewan Uji}

Punggung tikus dicukur terlebih dahulu dan dibuat lingkaran berdiameter kurang lebih $3 \mathrm{~cm}$ dengan spidol untuk memudahkan pengamatan sebelum dilukai. Daerah yang akan diinsisi didesinfeksi dengan alkohol 70\%, dianestesi terlebih dahulu dan kemudian dengan menggunakan skapel, punggung memberikan perlakuan (salep daun sirih, povidon iodine, dan vaselin album).

\section{Pengukuran Hasil Penelitian}

Hasil penelitian diukur melalui proses pengamatan pada luka iris atau observasi pada subjek mengenai tingkat percepatan peyembuhan luka iris. Hal yang diamati adalah penutupan luka iris oleh kulit yang baru pada setiap subjek di semua kelompok. Luka iris yang telah bertaut dan tertutup oleh jaringan kulit baru dianggap telah sembuh. Hewan uji yang telah dikelompokkan tersebut dikandangkan dan diberi olesan ekstrak daun sirih sekali sehari. Pengamatan dan pengukuran luka dilakukan selama 1-14 hari dan terus diamati hingga luka benarbenar tertutup. Untuk menghindari bias tikus dikandangkan dengan menggunakan kandang yang disekat sehingga 1 tikus 
berada di dalam 1 kandang sehingga tidak terjadi perebutan makanan yang dapat mengganggu proses penyembuhan luka iris pada tikus. Sterilitas dalam perlakuan juga harus sangat diperhatikan untuk memperoleh data yang baik.

\section{Analisis Data}

Setiap kelompok perlakuan diukur panjang lukanya dari hari ke-1 hingga hari ke-14, dengan masing-masing hewan diukur untuk mendapatkan panjang ratarata setiap kelompok perlakuan. Setelah hari ke-14, rata-rata panjang masingmasing kelompok dianalisa menggunakan Oneway Anova. Hasil tersebut kemudian dikonversikan ke dalam bentuk persen, dengan persamaan:

$$
\underline{P}=(20-\mathrm{pl}) \times 100 \%
$$

\section{0}

$\mathrm{P}=$ persentase kesembuhan luka iris $\mathrm{pl}=$ rata-rata panjang luka iris

Selanjutnya hasil tersebut dimasukkan ke dalam tabel persentase kesembuhan luka dan grafik yang menggambarkan proses kesembuhan luka iris dari hari ke hari melalui pengamatan panjang luka pada punggung tikus. Kemudian data setiap kelompok perlakuan dianalisis dengan tes Anova untuk mengetahui apakah terdapat perbedaan kecepatan kesembuhan (dalam hari) yang bermakna atau tidak.

\section{HASIL DAN PEMBAHASAN}

Waktu penyembuhan dari hasil penelitian dapat dilihat seperti pada tabel 1. Rerata lama penyembuhan luka iris pada hewan uji pada tiga kelompok dianalisis menggunakan Oneway Anova didapatkan nilai $\quad p<0,05, \quad$ yang menunjukkan bahwa perlakuan pada kelompok tikus tersebut berpengaruh terhadap lama penyembuhan luka.

Persentase kesembuhan luka iris pada kelompok perlakuan dapat dilihat seperti pada grafik 1. Persentase kesembuhan kelompok I mencapai 100\% pada hari ke-11, sedangkan kelompok II

Tabel 1. Waktu penyembuhan luka pada tikus percobaan

\begin{tabular}{llc}
\hline \multicolumn{1}{c}{ Kelompok } & N & Rerata penyembuhan (hari) \\
\hline Salep daun sirih & 10 & $10,8 \pm 0,422$ \\
Povidon iodin & 10 & $11,9 \pm 0,316$ \\
Vaselin album & 10 & $13,8 \pm 0,422$ \\
\hline
\end{tabular}




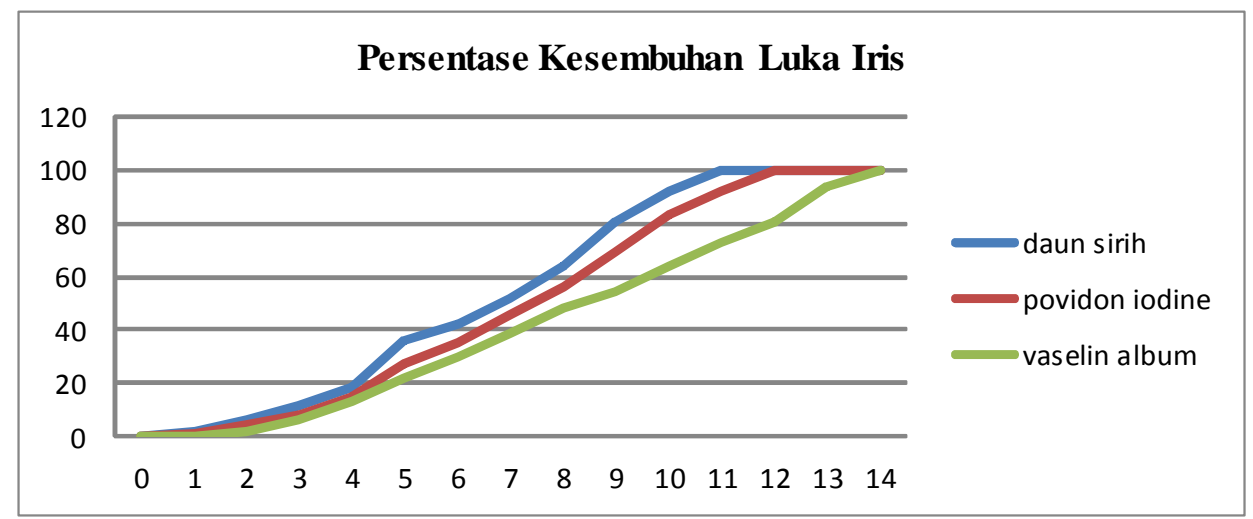

Grafik 1. Persentase kesembuhan luka iris pada berbagai kelompok perlakuan.

mencapai kesembuhan $100 \%$ pada hari penting dalam proses perbaikan ke-12 dan kelompok III mencapai jaringan. ${ }^{17}$

kesembuhan $100 \%$ pada hari ke-14. Daun sirih juga mengandung

Berdasarkan uji Oneway Anova hidroxychavicol suatu senyawa didapatkan bahwa pemberian salep antiinflamasi yang berperan dalam ekstrak daun sirih dapat mempercepat mempercepat proses penyembuhan luka. proses penyembuhan luka iris dengan Senyawa hidroxychavicol mampu waktu $10,80 \pm 0,422$ hari.

Zat aktif yang terkandung dalam menekan ekspresi TNF- $\alpha$ pada netrofil manusia. ${ }^{18,19}$ Daun sirih juga memiliki daun sirih (Piper betle) berperan dalam daya antihistamin karena karena percepatan proses penyembuhan luka ini. kandungan minyak atsiri (essential oil) Daun sirih mengandung vitamin C, dan ekstrak etanolnya (ethanolic extract). ${ }^{6}$ dimana vitamin ini dapat meningkatkan Daun sirih (Piper betle) memiliki stimulasi pembentukan kolagen oleh sel kandungan senyawa saponin yang fibroblast. $^{15,16}$ Dari penelitian tersebut berfungsi sebagai antioksidan, antifungal, didapatkan hasil bahwa derivat vitamin $\mathrm{C}$, antimikroba. Aktivitas antioksidan yaitu magnesium ascorbyl phosphate dibuktikan dengan kemampuan mampu meningkatkan proliferasi sel dan membentuk hydroperoxide intermediates menstimulasi sintesis kolagen, karena yang mencegah kerusakan bio-molekular proliferasi kolagen adalah hal yang oleh radikal bebas. ${ }^{20,21}$ Daun sirih juga mampu meningkatkan jumlah kolagen IV 
yang merupakan jaringan penghubung dermo-epidermal atau dermo-epidermal junction pada kultur keratinosit manusia. ${ }^{22}$ Hasil penelitian ini menguatkan hasil penelitian sebelumnya dimana salep ekstrak etanol daun sirih dapat mempercepat proses penyembuhan luka.

\section{KESIMPULAN}

Berdasarkan hasil penelitian dan analisis data yang telah dikemukakan, maka dapat disimpulkan bahwa ekstrak etanol daun sirih mampu mempercepat proses penyembuhan luka. Lama penyembuhan luka iris kelompok uji dengan salep ekstrak etanol daun sirih, kelompok uji dengan povidon iodin dan kelompok uji dengan vaselin album berturut turut adalah 10,8 $\pm 0,422$; $11,9 \pm 0,316 ; 13,8 \pm 0,422$. Penelitian lebih lanjut sangat perlu dilakukan untuk mengetahui efek terhadap manusia, dosis dan sediaan yang efektif untuk digunakan, sehingga salep daun sirih dapat dimanfaatkan dan menjadi alternatif terapi baru untuk penyambuhan luka.

\section{DAFTAR PUSTAKA}

1. Yunilawati R. Minyak Atsiri Daun Sirih Sebagai Antibakteri Streptococcus mutans Dalam Pasta Gigi. Skripsi. Jurusan Kimia Fakultas Matematika dan Ilmu Pengetahuan Alam, Institut Pertanian Bogor. 2002.
2. Sukandar. Trend dan Paradigma Dunia Farmasi: Industri-Klinik-Teknologi Kesehatan Bandung, Institut Teknologi Bandung.2006.

3. Supardi, Susyanty. Penggunaan Obat Tradisional Dalam Upaya Pengobatan Sendiri di Indonesia (Analisis Data Susenas Tahun 2007). Pusat Penelitian dan Pengembangan Sistem dan Kebijakan Kesehatan. Jakarta. 2010;38:80-89.

4. Menteri Kesehatan Republik Indonesia. Keputusan Menteri Kesehatan Republik Indonesia Nomor 1076/Menkes/SK/VII/2003 Tentang Penyelenggaraan Pengobatan Tradisional. Jakarta. 2003:1-18.

5. Afidah, Susilaningrum. Pola tingkat keparahan korban kecelakaan lalu lintas dengan menggunakan regresi logistik multinominal (Studi Kasus: Kecelakaan Lalu Lintas di Surabaya). Fakultas Matematika dan Ilmu Pengetahuan Alam, Institut Teknologi Surabaya. 2010.

6. Hajare R. Darvhekar VM, Shewale A, Patil V. Evaluation of Antihistaminic Activity of Piper betle leaf in Guinea Pig. Afr J Pharm Pharacol. 2011;5(2): 113117.

7. Rahmah N, Rahman A. Uji Fungistatik Ekstrak Daun Sirih (Piper betle L.) Terhadap Candida albicans. Bioscience 2010;7:17-24.

8. Darwis. Potensi Sirih (Piper betle) Sebagai Tanaman Obat. Warta Tanaman Obat Indonesia 1992;1:9-11.

9. Sastroamidjojo S. Obat Asli Indonesia. Jakarta : Dian Rakyat.1997.

10. Sari LO. Pemanfaatan Obat Tradisional Dengan Pertimbangan Manfaat dan Keamananannya. MIK. 2006;3:1-7.

11. Ali I, Khan FG, Suri KA, Gupta BD, Satti NK, Dutt $P$, et al. In Vitro Antifungal Activity of Hidroxychavicol Isolated From Piper betle L. Ann Clin Microbiol Antimicrob 2007;9(7):1-9.

12. Hermawan A. Pengaruh Ekstrak Daun Sirih (Piper betle L.) Terhadap Pertumbuhan Staphylococcus aureus dan Escherichia coli Dengan Metode Difusi 
Disk. Skripsi. Fakultas Kedokteran Hewan Universitas Airlangga. 2007.

13. Syamsuhidayat SS, Hutapea JR. Inventaris Tanaman Obat Indonesia. Departemen Kesehatan Republik Indonesia. Jakarta.1991.

14. Arambewela L, Arawwawala LDAM, RatnasoOriya WD. Studies on Piper betle of Sri lanka. J Natl Sci Found 2005;33(2):133-139.

15. Pradhan D, Suri KA, Pradhan DK, Biswasroy P. Golden Heart of the Nature: Piper betle L. J Pharmacogn Phytochem 2013;1(6):147-167.

16. Tiedtke J, et al. Stimulation of Collagen Production in Human Fibroblast. Cosmetic Science Technology. 2007.

17. Zulaechah. Perbedaan Kecepatan Penyembuhan Luka Sayat Antara Penggunaan Lendir Bekicot (Achatina fulica) Dengan Povidone Iodine 10\% Dalam Perawatan Luka Sayat Pada Mencit (Mus musculus). Skripsi. Program Studi Ilmu Keperawatan Fakultas Kedokteran dan Ilmu Kesehatan, Universitas Muhammadiyah Yogyakarta. 2010.

18. Sharma S, Khan IA, Ali I, Ali F, Kumar M, Kumar A, et al. Evaluation of The Antimicrobal, Antioxidant, and Antiinflamatory Activities of
Hidroxychavicol for Its Potential Use As an Oral Care Agent. Antimicrob Agents Chemother 2009;53(1):216-222.

19. Bhattacharya S, Banerjee D, Bauri AK, Chattopadhyay S, Bandyyopadhyay SK. et al. Healing Property of The Piper betel Phenol, Allylpyrocatechol Against Indometachin-Induced Stomach Ulceration and Mechanism of Action. World J Gastroenterol 2007;13(2):37053713.

20. Francis G. Kerem Z, Makar HPS, Becker $K$. The Biological Action of Sapoinins in Animal Systems: A Review. Br J Nutr 2002;88:587-605.

21. Prabu MS, Muthumani M, Shagirta K. Protective Effect of Piper betle Leaf Extract Against Cadmium-Induced Oxidative Stress and Hepatic dysfunction in Rats. Saudi J Biol Sci 2012;10:1-11.

22. Bonte, Frederic, Dumas, Marc, Perrier, Pierre. Saponin or Sapogenol Compositions for Increasing Collagen IV Synthesis. United States Patent 2003:214.

23. Morison MJ. A colour Guide To The Nursing Management of Wounds. Tyasmono J. 2007 (Alih Bahasa). Jakarta:EGC. 2008, pp.1-27. 